FINANCIAL: Jurnal Akuntansi

Published by Program Studi Akuntansi STIE Sultan Agung

Volume 7-Nomor 1, Juni 2021, (Hlm 76-85)

ISSN-P: 2502-4574, ISSN-E: 2686-2581

Available online at: https://financial.ac.id/index.php/financial

\title{
DETERMINASI HARGA SAHAM PERUSAHAAN TRANSPORTASI YANG TERDAFTAR DI BURSA EFEK INDONESIA TAHUN 2015-2019
}

\author{
Alviony Charisa Putri ${ }^{1)^{*}}$, Arif Nugroho Rachman ${ }^{2)}$ \\ ${ }^{1,2}$ STIE Surakarta, J1. Slamet Riyadi No.435-437, Dusun I, Makamhaji, Kec. Kartasura, Kabupaten \\ Sukoharjo, Jawa Tengah 57161, Indonesia \\ E-mail: ${ }^{1}$ alvionycharisa@gmail.com , ${ }^{2}$ arifnugroho.rachman@gmail.com
}

\begin{abstract}
Abstrak
Tujuan dari penelitian ini adalah untuk mengetahui pengaruh Return on Asset (ROA), Return on Equity (ROE), Debt to Equity Ratio (DER), dan Current Ratio (CR) secara parsial terhadap harga saham perusahaan transportasi yang terdaftar di Bursa Efek Indonesia tahun 2015-2019. Pada penelitian ini menggunakan metode penelitian kuantitatif. Populasi pada penelitian ini adalah perusahaan sektor jasa transportasi yang terdaftar di Bursa Efek Indonesia (BEI) periode tahun 2015 sampai dengan 2019 sebanyak 46 perusahaan. Sampel yang digunakan adalah 15 perusahaan yang telah diseleksi dengan mengaplikasikan metode purposive sampling, yakni perusahaan yang terpilih hanya perusahaan yang memenuhi kriteria yang sudah ditentukan peneliti. Hasil penelitian yang dilakukan mengindikasikan bahwa secara parsial seluruh variabel yaitu ROA, ROE, DER dan CR memberikan pengaruh positif signifikan terhadap harga saham perusahaan transportasi yang terdaftar di BEI tahun 2015-2019. Hal ini berarti apabila nilai variabel ROA, ROE, CR dan DER meningkat akan menyebabkan peningkatan pada harga saham perusahaan transportasi yang terdaftar di BEI tahun 2015-2019, begitu juga sebaliknya. Saran bagi perusahaan adalah agar dapat meningkatkan nilai perusahaan dengan langkah yang efektif untuk dapat meningkatkan laba perusahaan.
\end{abstract}

Kata kunci: Return on Asset, Return on Equity, Debt to Equity Ratio, Current Ratio, Harga Saham

\section{THE STOCK PRICE DETERMINATION OF TRANSPORTATION COMPANIES REGISTERED IN INDONESIA STOCK EXCHANGE IN 2015-2019}

\begin{abstract}
This study aims to determine the influence of Return on Assets (ROA), Return on Equity (ROE), Debt to Equity Ratio (DER), and Current Ratio (CR) partially towards the stock prices of transportation companies registered in Indonesia Stock Exchange in 2015-2019. This study used quantitative research method. The population in this study was 46 transportation service companies registered in Indonesia Stock Exchange (IDX) in the period of 2015 to 2019. The sample used was 15 companies that have been selected by applying purposive sampling method. Those selected companies were companies that meet the criteria determined by the researcher. The results of the research conducted indicated that partially, all variables, namely ROA, ROE, DER and $C R$, have a significant positive influence towards the stock prices of transportation companies registered in the IDX in 2015-2019. It means that if the value of the variables ROA, ROE, CR and DER increases, it will cause an increase in the stock prices of transportation companies registered in the IDX in 2015-2019, and vice versa. It is recommended that the companies can increase its value with effective steps to increase company profits.
\end{abstract}

Keywords: Return on Asset, Return on Equity, Debt to Equity Ratio, Current Ratio, Stock Price

Article History: Received: 31 Mar 2021 Revised: 22 Apr 2021 Accepted: 08 Mei 2021 


\section{PENDAHULUAN}

Semakin berkembangnya perekonomian, semakin berkembang pula kebutuhan masyarakat di Indonesia. Salah satunya kebutuhan dalam bidang transportasi darat, laut ataupun udara. Hal ini dibuktikan dengan Produk Domestik Bruto (PDB) sub sektor transportasi pada tahun 2019 mengalami pertumbuhan sebesar 9,29\% (Setijadi, 2020). Transportasi berperan penting dalam menunjang pembangunan ekonomi masyarakat dan ekonomi negara. Oleh sebab itu, pembangunan ekonomi harus diimbangi dengan pembangunan transportasi agar pembangunan ekonomi dapat berjalan dengan lancar.

Seiring dengan perkembangan zaman, berkembang pula inovasi transportasi di Indonesia. Salah satu contohnya adalah PT. Aplikasi Karya Anak Bangsa (Gojek), meski terbilang baru namun kemunculan Gojek pada tahun 2010 menjadi ancaman bagi perusahaan transportasi sejenis. Perusahaan transportasi yang sudah ada harus mampu berinovasi demi menjaga keberlanjutan usahanya. Oleh karena itu, untuk mendukung perkembangan industri transportasi diperlukan tambahan modal bagi perusahaan baik dari lembaga keuangan maupun investor.

Pasar modal menjadi wadah yang tepat bagi perusahaan yang membutuhkan modal serta bagi para investor yang ingin menginvestasikan dananya. Patabang \& Purnomo (2019) menyatakan saham adalah sebuah instrumen keuangan yang diperjualbelikan di pasar modal dan mengindikasikan kepemilikan atas sebuah perusahaan, serta otomatis mempunyai hak atas laba perusahaan yang pembagiannya diwujudkan dalam bentuk deviden. Ketika investor menginvestasikan dananya ke instrumen saham, tentu investor tersebut berharap memperoleh pendapatan dari deviden dan capital gain, tetapi tidak dipungkiri bahwa dalam investasi saham terdapat resiko investor mengalami capital loss. Mengutip dari laman Otoritas Jasa Keuangan (OJK), perubahan harga saham disebabkan oleh faktor internal dan eksternal seperti: kondisi mikro ekonomi, fluktuasi kurs rupiah terhadap kurs asing, kebijakan pemerintah, kepanikan investor, faktor manipulasi pasar, fundamental perusahaan, aksi korporasi perusahaan dan proyeksi kinerja perusahaan masa mendatang. Perubahan harga saham tentu dapat memengaruhi keuntungan yang diterima oleh investor (Otoritas Jasa Keuangan, 2019).

Meningkatnya pertumbuhan ekonomi akan diiringi oleh peningkatkan kebutuhan transportasi di Indonesia seiring dengan perkembangan infrastruktur. Oleh sebab itu, saham perusahaan sub sektor transportasi menjadi sebuah opsi bagi para investor untuk berinvestasi. Sebelum melakukan investasi tentunya investor melakukan analisis terhadap kondisi perusahaan. Salah satunya adalah analisis terhadap laporan keuangan perusahaan.

Dalam penelitian ini, faktor yang memengaruhi harga saham perusahaan diklasifikasi menjadi empat, yaitu Return on Asset (ROA), Return on Equity (ROE), Debt to Equity Ratio (DER), dan Current Ratio (CR). Hasil penelitian Ekawati \& Yuniati (2020) mengindikasikan bahwa ROA secara negatif signifikan memengaruhi harga saham, sementara penelitian Patabang \& Purnomo (2019), serta Mandasari \& Triyonowati (2019) menyebutkan ROA memberi pengaruh positif signifikan pada harga saham. Penelitian yang dilakukan oleh Ekawati \& Yuniati (2020) menyatakan bahwa ROE secara positif signifikan memengaruhi harga saham. Sementara 
penelitian Patabang \& Purnomo (2019) menyatakan bahwa ROE maupun DER memberi pengaruh negatif tidak signifikan pada harga saham. Namun hasil penelitian yang dilakukan oleh Mandasari \& Triyonowati (2019) menyatakan bahwa DER secara positif signifikan memengaruhi harga saham. Kemudian penelitian yang dilakukan oleh Aristanti \& Utiyati (2018) menyatakan CR memiliki pengaruh signifikan terhadap harga saham, sementara penelitian yang dilakukan oleh Aspriyadi (2020) menyatakan CR tidak memberikan pengaruh signifikan terhadap harga saham.

Berdasarkan fenomena penelitian ini bertujuan untuk mengetahui pengaruh ROA, ROE, DER dan CR terhadap harga saham perusahaan transportasi yang terdaftar di BEI.

\section{LANDASAN TEORI}

Pendapat Murhadi (2013) menyatakan bahwa laporan keuangan memuat keterangan yang ada keterkaitannya dengan situasi keuangan perusahaan bagi pihak yang mempunyai kepentingan untuk meninjau perihal sehat atau tidaknya kondisi keuangan. Pembuatan laporan keuangan ditujukan agar dapat memberi sejumlah informasi yang berkenaan dengan posisi keuangan, termasuk kinerjanya, ataupun perubahannya pada posisi tersebut, yang akhirnya dapat dilakukan analisis yang bisa diperhitungkan dalam membuat keputusan ekonomi.

Analisis rasio diterapkan dengan memperbandingkan antara suatu angka dari sebuah akun dengan angka akun yang lain. Perbandingannya dianalisis secara relatif, dimana hal ini ditujukan sebagai langkah preventif agar dapat meminimalkan munculnya kekeliruan interpretasi pada angka mutlak pada laporan keuangan. Adapun rasio keuangan yang diaplikasikan pada penelitian ini di antaranya yaitu rasio likuiditas, rasio solvabilitas, dan rasio profitabilitas (Murhadi, 2013)

ROA memberi gambaran tentang return yang dimunculkan dari setiap rupiah uang di mana investasinya diwujudkan dalam bentuk aset. Laba yang didapatkan akan semakin banyak jika nilai ROA mengalami peningkatan (Murhadi, 2013). Pendapat Rahardjo (2009) menyatakan DER sebagai perbandingan semua utang jangka panjang ataupun jangka pendek dengan jumlah modal yang dimiliki perusahaan. Kenaikan tingkat DER akan diiringi dengan peningkatan risiko perusahaan (Murhadi, 2013).

CR sebagai rasio yang digunakan untuk mengukur kapabilitas (kemampuan) perusahaan perihal pembayaran untuk liabilitas jangka pendek yang jatuh tempo dalam waktu setahun. Rasio lancar yang dianjurkan yaitu sebanyak 2. Jika terlalu tinggi, hal ini menandakan adanya penyimpanan aset lancar yang terbilang eksesif. Sementara jika terlalu rendah, hal ini merefleksikan liabilitas yang akan jatuh tempo tidak sanggup dipenuhi oleh risiko perusahaan (Murhadi, 2013).

Menurut Darmadji \& Fakhruddin (2012) saham adalah tanda penyertaan atau kepemilikan dalam suatu perseroan terbatas. Saham berwujud selembar kertas yang didalamnya menerangkan bahwa pemilik saham tersebut adalah pemilik perusahaan penerbit surat berharga. Harga saham mempunyai relevansi dengan ditutupnya pasar saham pada waktu berlangsungnya pengamatan pada setiap jenis saham yang menjadi sampel, di mana investor mengamati pergerakan yang terjadi. Berubahnya harga saham berlangsung dalam waktu singkat. Nilai harga pasar saham yang semakin naik akan menaikkan ketertarikan investor untuk melakukan penjualan pada saham mereka 


\section{METODE}

Penelitian merupakan penelitian kuantitatif kausal komparatif. Menurut Sugiyono (2015), penelitian kuantitatif diinterpretasikan sebagai penelitian yang bertumpu atau dilandaskan pada filsafat positivisme, diterapkan untuk mengkaji suatu populasi atau sampel, di mana datanya dikumpulkan dengan mengaplikasikan instrumen penelitian dan analisisnya bersifat statistik, serta ditujukan untuk melakukan pengujian pada hipotesis yang sudah ditetapkan.

Penelitian kausal komparatif dijalankan agar dapat menginvestigasi hubungan kausal (sebab-akibat) yang didasarkan pada pengamatan atas dampak yang muncul dan menyelami lebih lanjut perihal faktor yang memicu kemunculan dampak tersebut lewat data yang sudah terkumpul. Populasi pada penelitian ini adalah 46 perusahaan sektor transportasi yang terdaftar di Bursa Efek Indonesia (BEI) periode tahun 2015-2019 (Idx.co.id, 2021).

Dalam pengambilan sampel, peneliti menerapkan metode purposive sampling. Sampel yang digunakan dalam penelitian ini berdasarkan pada sejumlah kriteria yang harus diperhatikan, di antaranya: (1) perusahaan yang bergerak di bidang transportasi yang terdaftar di BEI; (2) perusahaan yang memublikasikan laporan keuangannya secara rinci periode tahun 2015-2019; dan (3) perusahaan yang tercatat pada papan utama di BEI. Dengan berdasarkan pada kriteria tersebut, maka dari 46 populasi, didapatkan 15 sampel perusahaan transportasi yang menenuhi kriteria tersebut. Daftar perusahaan dapat dicermati pada Tabel 1.

Copyright (C) 2021, FINANCIAL: Jurnal Akuntansi
Tabel 1. Daftar Perusahaan Transportasi Periode 2015-2019 yang Dijadikan Sampel

\begin{tabular}{|c|c|l|}
\hline No & Kode & \multicolumn{1}{|c|}{ Perusahaan } \\
\hline 1 & ASSA & Adi Sarana Armada Tbk. \\
\hline 2 & BIRD & Blue Bird Tbk. \\
\hline 3 & HITS & $\begin{array}{l}\text { Humpuss Intermoda Transportasi } \\
\text { Tbk. }\end{array}$ \\
\hline 4 & SOCI & Soechi Lines Tbk. \\
\hline 5 & TMAS & Temas Tbk. \\
\hline 6 & BBRM & $\begin{array}{l}\text { Pelayaran Nasional Bina Buana } \\
\text { Raya Tbk. }\end{array}$ \\
\hline 7 & BLTA & Berlian Laju Tanker Tbk. \\
\hline 8 & BULL & Buana Lintas Lautan Tbk. \\
\hline 9 & GIAA & Garuda Indonesia (Persero) Tbk \\
\hline 10 & LEAD & Logindo Samudramakmur Tbk. \\
\hline 11 & MBSS & Mitrabahtera Segara Sejati Tbk \\
\hline 12 & SMDR & Samudera Indonesia Tbk. \\
\hline 13 & TAXI & Express Transindo Utama Tbk. \\
\hline 14 & WEHA & $\begin{array}{l}\text { WEHA Transportasi Indonesia } \\
\text { Tbk. }\end{array}$ \\
\hline 15 & WINS & Wintermar Offshore Marine Tbk. \\
\hline
\end{tabular}
Sumber : Data diolah peneliti (2021)

Jenis data yang digunakan adalah data dokumenter. Data yang peneliti gunakan yaitu laporan keuangan tahunan yang dipublikasi secara lengkap (periode tahun 2015-2019) oleh perusahaan transportasi. Data yang terkumpul didapatkan dengan menghimpun informasi lewat teknik pengumpulan data sekunder yakni data kuantitatif, di mana datanya ditampilkan dalam wujud angka yang tertera pada laporan keuangan perusahaan sektor transportasi yang ada di BEI tahun 2015-2019.

Variabel dibedakan menjadi dua yaitu variabel independen (bebas) dan variabel dependen (terikat). Adapun variabel independen dalam penelitian ini yaitu ROA, ROE, DER dan CR, sementara variabel dependennya adalah harga saham.

Menurut Kasmir (2016) ROA digunakan untuk mengindentifikasi keefektifan perusahaan dalam penggunaan aktiva yang dimilikinya agar laba dapat dihasilkan. Penentuan rasio ROA dengan menggunakan rumus berikut: 


$$
\mathrm{ROA}=\frac{\text { Net Income }}{\text { Total Asset }}
$$

Menurut Kasmir (2012), ROE digunakan untuk mengetahui keefektifan perusahaan dalam menggunakan modal sendiri. Rumus penentuan rasio ROE yaitu:

$$
\mathrm{ROE}=\frac{\text { Net Income }}{\text { Total Equity }}
$$

Menurut Kasmir (2012), DER digunakan untuk mengukur utang dengan ekuitas, yang fungsinya untuk melihat setiap rupiah modal sendiri yang menjadi jaminan utang. Pengukuran DER mengaplikasikan satuan ukuran \% (persen). Rumus penentuan rasio DER yaitu:

$$
\mathrm{DER}=\frac{\text { Total Debt }}{\text { Total Equity }}
$$

Menurut Kasmir (2012) CR digunakan untuk mengetahui kapabilitas perusahaan dalam membayarkan kewajiban jangka pendeknya yang mendekati jatuh tempo pada waktu dilakukan penagihan secara menyeluruh. CR dihitung dengan memperbandingkan antara total aktiva lancar dan total utang lancar. Penentuan rasio CR dengan mengaplikasikan rumus berikut:

$$
\mathrm{CR}=\frac{\text { Current Assets }}{\text { Current Liabilities }}
$$

Pengolahan data mengaplikasikan Statistical Program for Social Science (SPSS). Dengan model persamaan sebagai berikut:

$$
\begin{gathered}
\mathrm{HS}=\alpha+\beta 1 \mathrm{ROA}+\beta 2 \mathrm{ROE}+\beta 3 \mathrm{DER}+ \\
\beta 4 \mathrm{CR}+\varepsilon
\end{gathered}
$$

Keterangan :

$$
\begin{array}{ll}
\text { HS } & : \text { Harga Saham } \\
\alpha & : \text { Konstanta } \\
\beta & : \text { Koefisien regresi } \\
\text { ROA } & : \text { Return on Asset } \\
\text { ROE } & : \text { Return on Equity } \\
\text { DER } & : \text { Debt to Equity Ratio } \\
\text { CR } & : \text { Current Ratio } \\
\varepsilon & : \text { Error }
\end{array}
$$

\section{HASIL DAN PEMBAHASAN}

Dari hasil statistik deskriptif yang disajikan pada tabel 2 menunjukkan ROA, didapatkan nilai minimum $-65,90$ dan nilai maksimumnya 17,80 . Nilai rata-rata ROA adalah -2,9609, sementara standar deviasi ROA sebesar 13,28121. ROE memiliki nilai minimum $-125,16$, dan nilai maksimumnya adalah 60,80. Nilai rata-rata ROE adalah 2,7520, dengan standar deviasi ROE 24,82336. DER memiliki nilai minimum 3,17 , dan nilai maksimum 120 . Nilai rata-rata DER adalah 4,0727, sementara standar deviasi DER sebesar 16,24720. CR memiliki nilai minimum 0,09 , dan nilai maksimumnya adalah 52. Nilai rata-rata CR 2,2069, dan standar deviasi CR 7,07550. Hasil statistik deskriptif Harga Saham mengindikasikan nilai minimum yaitu 50, dengan nilai maksimum 7100. Nilai rata-rata harga saham adalah 488,5769, sementara standar deviasi sebesar 1006,70622.

Tabel 2. Statistik Deskriptif

\begin{tabular}{|l|r|r|r|r|r|}
\hline & N & Min. & Maks. & Mean & Std. Deviasi \\
\hline ROA & 75 & -65.90 & 17.80 & -2.9609 & 13.28121 \\
\hline ROE & 75 & -125.16 & 60.80 & -2.7520 & 24.82336 \\
\hline DER & 75 & -3.17 & 120.00 & 4.0727 & 16.24720 \\
\hline CR & 75 & .09 & 52.00 & 2.2069 & 7.07550 \\
\hline HS & 75 & 50.00 & 7100.00 & 488.5769 & 1006.70622 \\
\hline
\end{tabular}

Sumber: Data diolah peneliti (2021)

Dari hasil perhitungan yang tersaji pada Tabel 3, didapatkan persamaan regresi linier berganda berikut ini:

$$
\begin{aligned}
& \mathrm{HS}=575,153+16,949 \mathrm{ROA}+4,964 \\
& \mathrm{ROE}+4,975 \mathrm{DER}+1,119 \mathrm{CR}+\mathrm{e}
\end{aligned}
$$

Dari persamaan regresi di atas, maka dapat disimpulkan yaitu: Konstanta $(\alpha)$ : nilai $(\alpha)$ sebanyak 575,153 mengindikasikan bahwa pada seluruh variabel bebas, nilai $(\alpha)$ terhadap variabel terikat sebanyak 575,153 pada perusahaan transportasi. 
Koefisien Regresi ROA mengindikasikan nilai $\beta 1$ sebanyak 16,949, berarti ROA berhubungan positif (searah) dengan harga saham. Interpretasinya, semakin tinggi nilai ROA akan seiring dengan peningkatan harga saham, begitu pun kebalikannya. Singkat kata, ROA mengalami peningkatan sebanyak $\beta 1$ yakni 16,949 dengan mengasumsikan bahwa variabel bebasnya adalah konstan.

Koefisien Regresi ROE memperlihatkan nilai $\beta 2$ sebanyak 4,964 . Hal ini mengindikasikan adanya hubungan positif antara ROE dengan harga saham. Interpretasinya, nilai ROE yang mengalami peningkatan akan diiringi dengan meningkatnya harga saham, begitu pun kebalikannya. Oleh sebab itu, ROE meningkat sebanyak $\beta 2$ yakni 4,964 dengan mengasumsikan variabel bebas lainnya tergolong konstan.

\section{Koefisien Regresi DER}

mengindikasikan nilai $\beta 3$ sebanyak 4,975. Hal ini berarti DER berhubungan searah dengan harga saham. Interpretasinya, jika nilai DER naik, maka naiknya harga saham pun akan mengalami kenaikan, begitu pun kebalikannya. Oleh karenanya, DER mengalami peningkatkan sebanyak $\beta 3$ yakni 4,975 dengan mengasumsikan bahwa variabel bebas lainnya adalah konstan.

$$
\text { Koefisien Regresi CR }
$$

mengindikasikan nilai $\beta 4$ sebanyak 1,119 yang menandakan bahwa $\mathrm{CR}$ mempunyai hubungan positif dengan harga saham. Interpretasinya, peningkatan nilai $\mathrm{CR}$ akan memicu peningkatan harga saham, begitu pun kebalikannya. Singkat kata, CR mengalami peningkatan sebanyak $\beta 4$ yakni 1,119 dengan mengasumsikan bahwa variabel bebas lainnya adalah konstan.
Tabel 3. Hasil Uji Regresi Linier Berganda

\begin{tabular}{|l|c|c|c|c|}
\hline \multirow{2}{*}{ Model } & $\begin{array}{c}\text { Unstand } \\
\text { ardized } \\
\text { Coefficie } \\
\text { nts }\end{array}$ & $\begin{array}{c}\text { Standar } \\
\text { dized } \\
\text { Coeffici } \\
\text { ents }\end{array}$ & $\mathrm{t}$ & Sig. \\
\cline { 2 - 5 } & $\mathrm{B}$ & Beta & & \\
\hline (Constant) & 575.153 & & 4.646 & .000 \\
\hline ROA & 16.949 & .224 & 4.774 & .008 \\
\hline ROE & 4.964 & .122 & 3.974 & .003 \\
\hline DER & 4.975 & .080 & 2.634 & .028 \\
\hline CR & 1.119 & .008 & 2.062 & .015 \\
\hline
\end{tabular}

Sumber: Data diolah peneliti (2021)

Hasil uji normalitas KS menyatakan bahwa Asymp. Sig. (2-tailed) =0,053 lebih tinggi daripada tingkat signifikansi $(\alpha)=5 \%$ $(0,05)$. Hal ini menandakan residual persamaan regresi berdistribusi normal. Berdasarkan uji normalitas yang telah dilakukan oleh peneliti, hasil memperlihatkan titik-titiknya memencar di area garis diagonal dan mengiringi garis tersebut. Kesimpulannya yaitu data mempunyai distribusi normal. Singkat kata, asumsi normalitas pada model regresi sudah terpenuhi.

Dengan mencermati nilai VIF pada Tabel 4, tampak nilai VIF pada seluruh variabel ROA, ROE, DER, dan CR posisinya ada di bawah 10. Hal ini berarti tidak dijumpai gejala multikolinieritas antar variabel bebas pada uji ini sebab seluruh nilai VIF-nya di bawah angka 10.

Tabel 4. Nilai VIF Variabel Bebas

\begin{tabular}{|l|r|r|}
\hline \multirow{2}{*}{ Model } & \multicolumn{2}{|c|}{ Collinearity Statistics } \\
\cline { 2 - 3 } & Tolerance & \multicolumn{1}{c|}{ VIF } \\
\hline ROA & .818 & 1.223 \\
\hline ROE & .823 & 1.215 \\
\hline DER & .809 & 1.237 \\
\hline CR & .811 & 1.234 \\
\hline
\end{tabular}

Sumber: Data diolah peneliti (2021)

Pendeteksian autokorelasi bisa diketahui dengan cara membuat keputusan dengan menerapkan uji DW (Ghozali, 2017). Hasil perhitungan dalam uji DW yaitu: 
Tabel 5. Hasil Auto Korelasi

\begin{tabular}{|r|r|r|}
\hline Model & R & Durbin-Watson \\
\hline 1 & $.652^{\mathrm{a}}$ & 1.947 \\
\hline
\end{tabular}

Sumber: Data diolah peneliti (2021)

Tabel 5 mengindikasikan nilai uji DW = 1,947. Uji DW ini mengaplikasikan $\alpha=5 \%$. Dengan banyaknya sampel $(\mathrm{n})=75$ dan banyaknya variabel independen $(\mathrm{k})=4$ maka $\mathrm{dL}=1,515$ dan $\mathrm{dU}=1,739$. Tabel diagnosis autokorelasi tersaji pada tabel 6 .

Tabel 6. Kriteria Pengambilan Keputusan Durbin-Watson

\begin{tabular}{|c|c|}
\hline Nilai Statistik DW & Kesimpulan \\
\hline $0<1,515$ & Autokorelasi Positif \\
\hline $1,515 \leq 1,947 \leq 1,739$ & Tanpa Keputusan \\
\hline $1,739 \leq 1,947 \leq 2,261$ & Tidak Ada \\
& Autokorelasi \\
\hline $2,261 \leq 1,947 \leq 2,485$ & Tanpa Keputusan \\
\hline $1,947 \geq 2,485$ & Autokorelasi Negatif \\
\hline
\end{tabular}

Sumber: Data diolah peneliti (2021)

Tabel 6 mengindikasikan nilai statistik uji DW $=1,947$. Uji DW $\alpha=5 \%$. Dengan banyaknya sampel $(\mathrm{n})=75$ dan banyaknya variabel independen $(\mathrm{k})=4$ maka $\mathrm{dL}=1,515$ dan $\mathrm{dU}=1,739$. Maka, nilai $4-\mathrm{dL}=2,485$ dan $4-d U=2,261$. Singkat kata, pengujian DW berada pada area yang tidak menampakkan terdapatnya autokorelasi.

Uji heterokedastisitas dilakukan untuk mengindentifikasi kemunculan perbedaan varian dari nilai residual pada model regresi. Pendeteksian gejalanya bisa diketahui dengan mencermati kemunculan suatu pola khusus pada grafik pengujian heteroskedastisitas. Menurut Ghozali (2017), model regresi yang baik adalah tidak terjadi heterokedastisitas. Berdasarkan uji yang telah dilakukan memperlihatkan adanya titik yang penyebarannya berada di atas dan di bawah sumbu Y dan tidak menampakkan pola khusus. Singkat kata, heteroskedastisitas tidak terjadi pada penelitian ini.

Copyright (C) 2021, FINANCIAL: Jurnal Akuntansi
Uji koefisien determinasi digunakan untuk mengukur kemampuan model dalam menerangkan variasi variabel dependen (Ghozali, 2017). Di bawah ini disajikan hasil output yang didapatkan dengan mengaplikasikan program SPSS. Hasil uji koefisien determinasi (R2) tersaji pada Tabel 7 .

Tabel 7. Hasil Uji Koefisiensi Determinasi

\begin{tabular}{|c|c|c|}
\hline \multicolumn{1}{|c|}{ Model } & R & R Square \\
\hline 1 & $.652^{\mathrm{a}}$ & .425 \\
\hline
\end{tabular}

Sumber: Data diolah peneliti (2021)

Tabel 7 mengindikasikan R2 sebanyak 0,425 atau $42,5 \%$. Hal ini memperlihatkan terdapatnya $\mathrm{R} 2$ yang berjumlah $42,5 \%$ dalam hubungan pengaruh ROA, ROE, DER, dan CR terhadap harga saham. Hal ini menandakan variasi variabel harga saham yang diterangkan oleh ROA, ROE, DER, dan CR sebanyak 42,5\%, sementara sisanya $(57,5 \%)$ mendapat pengaruh dari variabel lain di luar penelitian.

Uji t ditujukan untuk menguji hipotesis tentang pengaruh variabel independen (ROA, ROE, DER dan CR) terhadap variabel dependen (harga saham) dengan tingkat signifikan 0,05 atau $\alpha=5 \%$. Berikut ini disajikan hasil pengelolaan data yang didapatkan dengan mengaplikasikan program SPSS. Hasil uji t bisa dicermati pada tabel 8 .

Tabel 8. Hasil Uji t

\begin{tabular}{|l|r|r|}
\hline \multicolumn{1}{|c|}{ Model } & \multicolumn{1}{c|}{$\mathrm{t}$} & \multicolumn{1}{c|}{ Sig. } \\
\hline (Constant) & 4.646 & .000 \\
\hline ROA & 4.774 & .008 \\
\hline ROE & 3.974 & .003 \\
\hline DER & 2.634 & .028 \\
\hline CR & 2.062 & .015 \\
\hline
\end{tabular}

Sumber: Data diolah peneliti (2021)

Dari tabel 8, terlihat nilai signifikansi dari variabel ROA terhadap harga saham (Y) 
sebanyak 0,080 , di mana nilai ini masih di bawah tingkat signifikan $(\alpha=5 \%)$ atau 0,008 $<0,05$. Hal ini menandakan terdapatnya penolakan pada hipotesis nol (H0), sementara H1 diterima. Kesimpulannya, ROA secara signifikan memengaruhi harga saham.

Pada tabel 8 memperlihatkan nilai signifikansi dari variabel ROE terhadap harga saham sebanyak 0,003 . Nilai signifikan $(0,003)$ tidak melebihi tingkat signifikan $(\alpha=$ $5 \%$ ) atau $0,003<0,05$. Hal ini menandakan terdapatnya penolakan pada $\mathrm{H} 0$, sementara $\mathrm{H} 2$ diterima. Kesimpulannya, pengaruh ROE terhadap harga saham terbilang signifikan.

Dari Tabel 8, tampak nilai signifikansi variabel DER terhadap harga saham sebanyak 0,028 di mana nilai ini lebih rendah dibanding tingkat signifikan $(\alpha=5 \%)$ atau $0,028<0,05$. Hal ini mengindikasikan terdapatnya penolakan pada $\mathrm{H} 0$, sementara H3 diterima. Kesimpulannya, DER secara signifikan memengaruhi harga saham.

Pada tabel 8 memperlihatkan nilai signifikansi dari variabel CR terhadap harga saham sebanyak 0,015 . Hasil nilai signifikan $(0,015)$ lebih rendah daripada tingkat signifikannya $(\alpha=5 \%)$ atau $0,015<0,05$. Hal ini menandakan hipotesis H0 ditolak, sementara H4 diterima. Kesimpulannya, pengaruh CR terhadap harga saham tergolong signifikan.

Hasil penelitian mengindikasikan bahwa ROA secara signifikan memengaruhi harga saham. Hal ini berarti kapabilitas perusahaan dalam mempergunakan semua aktivanya untuk mendapatkan laba setelah pajak terbilang tinggi. Oleh karenanya, analisis perusahaan semakin produktif sebab semua aktiva yang ada memunculkan laba. Sehingga akan menambah minat investor dalam membeli saham. Hasil penelitian ini searah dengan penelitian Patabang \& Purnomo (2019) dan Mandasari \&
Triyonowati (2019) yang menyebutkan ROA secara positif signifikan memengaruhi harga saham, tetapi hasil tersebut tidak searah dengan penelitian yang dijalankan Ekawati \& Yuniati (2020) yang menyebutkan ROA memberi pengaruh negatif signifikan pada harga saham.

Hasil penelitian mengindikasikan bahwa ROE secara signifikan memengaruhi harga saham. Hal ini menandakan kemampuan perusahaan dalam memanfaatkan investasi mampu memunculkan ketertarikan di mata investor yang akhirnya mereka berkenan dan berencana menanamkan sahamnya. Hasil penelitian ini senada dengan penelitian Ekawati \& Yuniati (2020) di mana penelitiannya menyebutkan ROE memberi pengaruh positif signifikan pada harga saham, tetapi penelitian Patabang \& Purnomo (2019) mengindikasikan ROE memberi pengaruh negatif tidak signifikan pada harga saham.

Hasil penelitian mengindikasikan bahwa DER secara positif memengaruhi harga saham. Interpretasinya, semakin rendah tingkat DER, hal ini akan memudahkan perusahaan untuk memperoleh dana dari investor. Hal ini senada dengan penelitian Mandasari \& Triyonowati (2019) yang menyebutkan DER memberi pengaruh positif signifikan pada harga saham. Namun penelitian yang dijalankan Patabang \& Purnomo (2019) mengindikasikan DER memberi pengaruh negatif yang tidak signifikan pada harga saham.

Hasil penelitian mengindikasikan bahwa CR secara signifikan memengaruhi harga saham. Singkat kata, tingginya $\mathrm{CR}$ akan memudahkan perusahaan untuk memperoleh dana dari investor. Hal ini selaras dengan penelitian Aristanti \& Utiyati (2018) yang menyebutkan harga saham mendapat pengaruh signifikan dari CR. Sementara 
penelitian yang dilakukan oleh Aspriyadi (2020) mengindikasikan CR tidak memberi pengaruh signifikan pada harga saham.

\section{SIMPULAN DAN SARAN}

Berdasarkan hasil penelitian yang sudah dijabarkan di atas, maka kesimpulan yang dapat disampaikan yaitu secara parsial Return on Asset (ROA) berpengaruh positif signifikan terhadap harga saham, Return on Equity (ROE) secara parsial berpengaruh positif signifikan terhadap harga saham, Debt to Equity Ratio (DER) secara parsial berpengaruh positif signifikan terhadap harga saham, dan Current Ratio (CR) secara parsial positif signifikan memengaruhi harga saham pada perusahaan transportasi yang ada di BEI. Berdasarkan hasil analisis dan kesimpulan yang tertera di atas, maka terdapat sejumlah saran yang dapat disampaikan bagi perusahaan, di antaranya yaitu agar dapat menaikkan nilai perusahaan, maka dibutuhkan adanya langkah yang dapat mengefektifkan aset dan hutang perusahaan, di mana hal ini ditujukan supaya laba yang dihasilkan dapat diimbangi dengan efektivitas. Selain itu, perusahaan disarankan untuk memerhatikan semua variabel yang dapat menaikkan harga sahamnya.

Bagi calon investor atau investor, sebelum melakukan investasi dianjurkan untuk memperhitungkan ROA, ROE, DER dan $C R$ sebagai pertimbangan dalam mengambil keputusan pada waktu melakukan investasi, karena secara parsial ROA, ROE, DER dan CR mempunyai pengaruh terhadap harga saham. Bagi penelitian berikutnya, untuk melakukan penelitian pada objek yang berbeda, lebih banyak jumlah sampelnya, periode tahunnya harus terbaru, dan mengaplikasikan variabel lain serta permodelan variabel mediasi.

Copyright (C) 2021, FINANCIAL: Jurnal Akuntansi

\section{DAFTAR PUSTAKA}

Aristanti, R. D., \& Utiyati, S. (2018). Pengaruh NPM, DER, CR, dan EPS Terhadap Harga Saham Pada Perusahaan Transportasi. Jurnal Ilmu dan Riset Manajemen (JIRM), 7(10).

Aspriyadi, D. (2020). Pengaruh Kinerja

Keuangan terhadap Harga Saham Perusahaan (Studi Kasus pada Perusahaan Jasa Transportasi yang Terdaftar di BEI Periode 2015-2019). Jurnal Ilmiah Ekonomi Bisnis, 6(3), 386-400.

Darmadji, T., \& Fakhruddin. (2012). Pasar Modal Di Indonesia. Jakarta: Salemba Empat.

Ekawati, S., \& Yuniati, T. (2020). Pengaruh ROA, ROE, dan EPS terhadap Harga Saham pada Perusahaan Transportasi. Jurnal Ilmu dan Riset Manajemen (JIRM), 9(2).

Ghozali, I. (2017). Ekonometrika Teori, Konsep, dan Aplikasi dengan IBM SPSS 24. Semarang: Penerbit Universitas Diponegoro.

Idx.co.id. (2021). Bursa Efek Indonesia. Diambil 10 Februari 2021, dari www.idx.co.id

Kasmir. (2012). Manajemen Perbankan. Jakarta: PT Raja Grafindo Persada.

Kasmir. (2016). Analisis Laporan Keuangan. Jakarta: PT Rajagrafindo Persada.

Mandasari, I., \& Triyonowat. (2019). Pengaruh ROA, PER, dan DER terhadap Harga Saham Perusahaan Transportasi di BEI. Jurnal Ilmu dan Riset Manajemen (JIRM), 8(2).

Murhadi, W. R. (2013). Analisis Laporan Keuangan: Proyeksi dan Valuasi Saham. Jakarta: Salemba Empat.

Otoritas Jasa Keuangan. (2019). Penyebab Naik Turun Harga Saham Suatu Perusahaan. Diambil 30 Maret 2021, dari

https://sikapiuangmu.ojk.go.id/FrontEnd /CMS/Article/10507

Patabang, E. N., \& Purnomo, H. (2019). Pengaruh Return on Equity (ROE), Return on Assets (ROA), earning per 
Share (EPS) dan Debt to Equity Rasio (DER) terhadap Harga Saham pada Perusahaan Transportasi yang Terdaftar di BEI Periode 2013-2017. Equilibrium Jurnal Bisnis \& Akuntansi, 13(2).

Rahardjo, B. (2009). Dasar-dasar Analisis Fundamental Saham Laporan KeuanganPerusahaan. Jakarta: Gajah Mada University Press.

Setijadi. (2020). PDB Sektor Logistik Indonesia 2019 Tumbuh 10,51\%, Proyeksi 2020 Akan Terkoreksi. Diambil 10 Februari 2021, dari https://supplychainindonesia.com/pdbsektor-logistik-indonesia-2019-tumbuh1051-proyeksi-2020-akan-terkoreksi/

Sugiyono. (2015). Metode Penelitian Kuantitatif Kualitatif dan $R \& D$. Bandung: Alfabeta. 